\title{
O PROCESSO DE FORMULAÇÃO ESTRATÉGICA A PARTIR DA PERSPECTIVA INDIVIDUAL: um estudo com executivos da indústria energética
}

\author{
Strategic formulation process from the individual perspective: \\ an energy industry executives study
}

\section{Rafael Lucian $^{[\mathrm{a}]}$, Aldemir Barretto Júnior ${ }^{[\mathrm{b}]}$, Walter Fernando Araújo de Moraes ${ }^{[\mathrm{c}]}$}

[a] Doutorando pela Universidade Federal de Pernambuco (UFPE), Pernambuco, PE - Brasil, e-mail: lucian@terra.com.br

[b] Mestre em Administração pela Universidade Federal de Pernambuco (UFPE), Pernambuco, PE-Brasil, e-mail: aldemir.jr@ig.com.br

[c] Pós-Doutorado em Administração pela University of Texas, Austin, EUA, professor da Universidade Federal de Pernambuco (UFPE), Pernambuco, PE - Brasil, e-mail: walter.moraes@pq.cnpq.br

\section{Resumo}

O objetivo deste estudo é discutir o processo de formulação estratégica a partir de uma perspectiva individual. Os mapas cognitivos têm um papel crucial na tomada de decisão dos estrategistas, e por esse motivo são na verdade os responsáveis pela formulação estratégica. Por meio de uma abordagem exploratório-descritiva, os executivos de uma grande empresa do setor elétrico são observados com o intuito de terem os seus mapas mentais compreendidos. A fase exploratória foi constituída de uma revisão literária que culminou com a construção de um instrumento de pesquisa, sendo este utilizado na segunda fase do estudo. As técnicas quantitativas utilizadas de análise fatorial, correlações não paramétricas e análise de regressão múltipla indicaram um modelo que apontou uma relação entre a formação estratégica deliberada, a ordem do nível hierárquico e a formação acadêmica.

Palavras-chave: Processo de formulação estratégica. Mapas cognitivos. Análise de regressões múltiplas.

\begin{abstract}
This paper aims to discuss the process of strategic formulation from an individual perspective. Cognitive maps have a crucial role in the decision of the strategists, and for this reason are actually responsible for strategy formulation. Through an exploratory-descriptive approach, the executives of a major company in the electricity sector are observed in order to have their mental maps included. The exploratory phase consisted of a literature review that led to the construction of a research instrument, which is used in the second phase of the study. The quantitative techniques used in factor analysis, nonparametric correlations and multiple regression analysis
\end{abstract}


indicated a model that showed a relationship between the deliberated training strategy, the order of hierarquic level and the academic education.

Keywords: Strategic formulation process. Cognitive maps. Multiple Regression analysis.

\section{INTRODUÇÃO}

Estrategistas têm como prática tomar decisões em seu dia a dia, sejam essas grandes ou pequenas, e de cunho profissional ou pessoal. Considerando a frequência dessa ação, tomar decisões deveria ser um processo fácil e bem entendido, mas na realidade não é. Tomar decisões é um processo complexo e quase não há estudos conclusivos sobre como ele ocorre.

Este artigo aborda o processo de formulação estratégica sob a perspectiva de como as decisões são tomadas em âmbito individual e está particularmente interessado em como o estrategista pensa. Entender a forma de pensar do estrategista é um modo de perceber as culturas dominantes e suas influências, assim como as prováveis decisões que serão tomadas pelo indivíduo.

Investigar pensamentos requer um estudo de como o mapa cognitivo do estrategista se apresenta. Mapas cognitivos são fontes de entendimento sobre a forma de o indivíduo abordar uma ampla gama de assuntos envolvendo a tomada de decisão e o raciocínio (JONHSON-LAIRD, 1983).

Este artigo busca um aprofundamento na teoria sobre formulação estratégica e, a partir dessa, desenvolve uma ferramenta de mensuração que investigará a forma de pensamento estratégico dos executivos do setor elétrico.

De Wit e Meyer (2004) sugeriram que a formulação estratégica está repleta de paradoxos. Paradoxo é a simultânea existência de dois estados de consciência (EISENHARDT, 2000). Cada estado do paradoxo é formado por argumentos e dimensões. Essas dimensões são individualmente estudadas em profundidade como base para a formação de uma escala de mensuração do pensamento estratégico que servirá como instrumento para o desenvolvimento deste estudo.

A delimitação da amostra pelo ramo de atuação profissional é baseada na literatura que aborda a cultura organizacional ou da indústria como fator importante na tomada de decisão estratégica.
Os autores da administração estratégica sustentam amplamente que, mesmo quando a estratégia emerge do coletivismo, ou é fruto da deliberação do estrategista chefe, a cultura possui um papel fundamental no processo (MINTZBERG; AHLSTRAND; LAMPEL, 2000, p. 197). Cultura é a força intangível que guia os atos e pensamentos através de um grupo de indivíduos. Welch (2005, p. 14) classifica cultura como a alma e o coração da empresa. A cultura no ambiente organizacional pode ser vista através de coisas tangíveis como a missão organizacional (MUSSELMAN, 2005).

A ferramenta de mensuração do pensamento estratégico, utilizada neste estudo, tem como proposta o melhor entendimento do mapa cognitivo do estrategista e a observação de como o indivíduo aceita ou evita as dimensões estratégicas propostas.

Dessa forma, este artigo está subdividido pelos seguintes tópicos: paradoxos da formulação estratégica, dimensões do processo de formulação estratégica, contextualização da empresa, construção do instrumento de mensuração do pensamento estratégico, método, análise dos dados e conclusões.

No desenvolvimento do instrumento de pesquisa foram consideradas as dimensões do pensamento estratégico, da formação estratégica e da mudança estratégica, segundo a proposta de abordagem De Wit e Meyer (2004). Em cada uma dessas dimensões pode ser observada uma tensão entre pelo menos duas correntes de pensamento opostas, que representam os extremos. Para observar, então, essas dimensões, é inicialmente necessário entender qual a implicação dos paradoxos no estudo da formulação estratégica. Esse assunto é abordado no próximo item.

\section{PARADOXOS DA FORMULAÇÃO ESTRATÉGICA}

O processo de formulação estratégica está repleto de paradoxos, e esses precisam ser entendidos 
para uma melhor observação do processo como um todo. De Wit e Meyer (2004) melhor definem paradoxo como uma situação em que dois fatores aparentemente contraditórios, ou mutuamente excludentes, parecem ser verdadeiros ao mesmo tempo.

Os paradoxos na verdade não possuem uma solução real e não há um meio lógico de integrar os dois opostos de forma perfeita em um problema (DE WIT; MEYER, 2004).

Este artigo se baseia nas tensões estratégicas - dimensões estratégicas do paradoxo. A Figura 1 explica as dimensões e as tensões que foram consideradas na observação do processo de formulação estratégica.
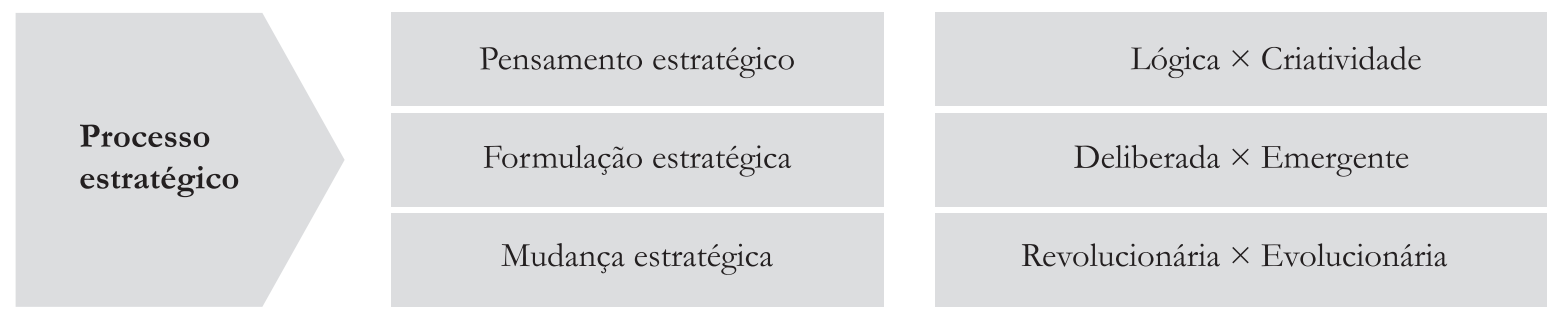

FIGURA 1 - Tensões do processo de formulação estratégica

Fonte: Adaptado de De Wit e Meyer, 2004, p. 13.

O próximo item abordará essas três dimensões e seus respectivos paradoxos.

\section{DIMENSÕES DO PROCESSO DE FORMULAÇÃO ESTRATÉGICA}

O pensamento estratégico, a formação estratégica e a mudança estratégica são as bases do processo de formulação estratégica.

O foco deste artigo é investigar a formulação estratégica a partir do nível de indivíduo, logo, o palco central do processo é a mente do estrategista. O mapa cognitivo representa a forma como o indivíduo pensa; portanto, entender como ele funciona é fundamental para observar a atuação das dimensões do processo de formulação estratégica.

\section{MAPAS COGNITIVOS E O PROCESSO DE FORMULAÇÃO ESTRATÉGICA}

Uma das escolas de estratégias citadas por Mintzemberg, Ahlstrand e Lampel (2000, p. 115) é a escola cognitiva, em que o processo de formação de estratégia é entendido como um processo mental.
Essa escola, baseada nos fundamentos da psicologia cognitiva, traz como argumento o fato de que para se compreender a visão estratégica e como as estratégias se formam é necessário sondar a mente do estrategista, ou seja, compreender seus modelos mentais e mapas cognitivos.

Mapas cognitivos são representações na mente das pessoas referentes ao modo como o mundo funciona, e esses mapas são muitas vezes formados através da educação, experiência e interação com os outros (DE WIT; MEYER, 2004).

O conceito de cognição está relacionado com a forma como as pessoas adquirem, armazenam e usam conhecimento (HAYES; ALLINSSON, 1994 apud NUNES, 2000).

O conceito de mapas cognitivos traz algumas importantes implicações. Em primeiro lugar, sugere que os decisores não se movem diretamente dentro da realidade dos fatos objetivos, mas dentro de uma realidade cognitiva, uma criação da realidade. Antes de ser um dado objetivo, o ambiente é uma representação tida como verdadeira pelos decisores (MACHADO-DA-SILVA; FONSCECA; FERNANDES, 2006, p. 7). 
Kahneman (2002, p. 451) apresenta dois modelos de funções cognitivas: um modo intuitivo, nos quais os julgamentos e decisões são tomados automaticamente e rapidamente, e um modelo controlado, que é deliberado e mais lento. Esse último considera as decisões tomadas com base em dois sistemas, sendo um intuitivo e outro racional. $\mathrm{O}$ esquema desses modelos é apresentado na Figura 2.

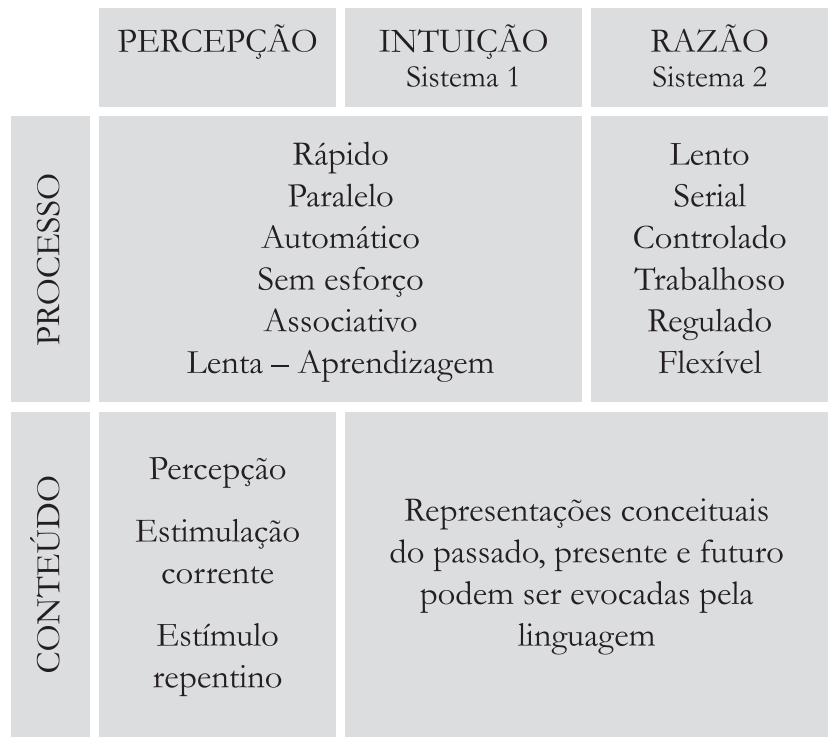

FIGURA 2 - Modelo de funções cognitivas

Fonte: KAHNEMAN, 2002, p. 451.

[...] os mapas cognitivos são como modelos descritivos que podem explicar os modos pelos quais as pessoas deduzem explicações do passado, fazem predições sobre o futuro e escolhem alternativas no presente. Entre as áreas em que os mapas cognitivos são utilizados como base de estudos empíricos estão: relações internacionais, política externa, impactos da crise energética e estratégias empresariais (MACHADO-DA-SILVA et al., 2006, p. 7).

\section{PENSAMENTO ESTRATÉGICO}

Entender a mente de um estrategista é extremamente importante para compreender seu processo de tomada de decisão. O processo lógico da estratégia envolve basicamente o pensamento estratégico e atividades cognitivas. Uma divisão pode ainda ser feita sobre atividades cognitivas: as que definem um problema e as que resolvem um problema.

Frequentemente as estratégias não são escolhidas em um leque potencial de opções. Elas são apenas inventadas através de metáforas, intuições ou fantasias baseadas no poder cognitivo do indivíduo.

Mapas cognitivos são produtos de anos de conhecimento e experiências acumuladas pelo indivíduo. A intuição não é uma maneira mística ou irracional de resolver problemas, ela é apenas uma forma lógica de resolver problemas com base somente nas orientações do mapa cognitivo.

A tensão existente na dimensão do pensamento estratégico é referente ao pensamento lógico e ao pensamento criativo. Estrategistas que pensam logicamente argumentam que os gerentes não podem basear suas decisões estratégicas apenas nos mapas cognitivos. Eles ainda concluem que decisões baseadas unicamente em experiências passadas ou na intuição tendem a resultados fracos.

O pensamento lógico evita que os gerentes falhem por usar processos que sejam ultrapassados ou influenciados por fatores emocionais. O pensamento racional ajuda, ainda, a distinguir as fantasias das possibilidades reais.

Pensamento lógico é o oposto do pensamento criativo. O pensamento estratégico lida com o modo como os estrategistas usam seus mapas cognitivos a partir de certa lógica ou criatividade no processo de formulação estratégica. O desenvolvimento do pensamento estratégico tem sido identificado como o maior problema enfrentado pelas organizações, e é sugerido como uma competência central (BONN, 2001).

Estrategistas que pensam criativamente não seguem nenhum conjunto de regras predeterminadas e possuem algumas crenças: utilizam a intuição como uma ferramenta de formulação estratégica; acreditam que seus mapas cognitivos possuem uma lógica oculta que, apesar de não compreendida, é válida para o desenvolvimento estratégico; não utilizam modelos de formulação estratégica, pois acreditam que esses são limitados e insuficientes; e consequentemente criam suas próprias soluções, que emergem de respostas inesperadas, mesmo que essa criatividade seja frágil e de entendimento complexo (MOORE, 2006, p. 39).

Rein $(2006$, p. 26) sugere que não apenas o estrategista deve ser criativo, mas toda a equipe 
precisa estar estimulada a ser criativa e inovadora. Inovação é o fator chave de um negócio inovador; logo, um ambiente que estimule a inovação e encoraje novas ideias pode tornar o negócio mais lucrativo (BERRIS, 2006, p. 40).

Sobre estimular a criatividade entre os funcionários, Cortello (2005, p. 26) argumenta que uma vez que a empresa crie um ambiente estimulador da criatividade, os empregados serão encorajados a reagir e se adaptar às condições de mudança. Mintzberg e Lampel $(1999$, p. 29) afirmam que a estratégia é movida pela criatividade do estrategista, pois assim novas formas de fazer as coisas são exploradas.

Para os estrategistas que pensam criativamente, a criatividade é identificada como uma parte importante do processo de formulação estratégica (STEINER; KUNIN; KUNIN, 1983). Para Mintzberg (1994), a criatividade é o centro do pensamento estratégico, e pensar criativamente em termos estratégicos é sugerido como a fonte da competitividade das organizações (RAIMOND, 1996).

Assim como o pensamento, a criatividade e a inteligência dos atores organizacionais estão ligados ao processo de aprendizagem organizacional. A forma como esse processo é desenvolvido se torna então uma questão chave, particularmente em um contexto múltiplo envolvendo aspectos tecnológicos, econômicos, sociais, políticos e culturais (MCGILL; BROCKBANK, 2004; DILWORTH; WILLIS, 2003; BOSHYK, 2002).

\section{FORMAÇÃO ESTRATÉGICA}

Formação estratégica é o ponto chave para o sucesso organizacional, e por isso demanda atenção de teóricos e práticos envolvidos no processo de formulação estratégica.

Basicamente, existem quatro passos para a formação estratégica: identificação, diagnóstico, concepção e realização. É importante, porém, entender que esses passos não representam necessariamente a melhor maneira de formar estratégias; são na verdade uma sugestão lógica para o processo.

O planejamento estratégico é comumente visto como um exercício analítico anual que funciona de cima para baixo, envolvendo apenas os altos executivos da empresa. Estratégia emergente é um processo contínuo de cima para baixo e de baixo pra cima que envolve as decisões diárias, ações e participação da organização como um todo. Estratégia emergente é basicamente relacionada com o aprendizado dos indivíduos da organização (REID, 1999, p. 13).

Há um perigo potencial relacionado com o planejamento estratégico formal: ele geralmente não considera novas ideias, aprendizado, inovação e ambiente político. Plano formal (estratégias deliberadas) e aprendizado contínuo (estratégias emergentes) são os extremos do paradoxo da formação estratégica.

Mintzberge Waters (1985, p. 257) estudaram as diferentes abordagens da formulação estratégica, baseadas em um continuum de estratégias deliberadas (planejamento) em um extremo e estratégias emergentes no outro lado. Eles concluíram que as formas puras não são encontradas na prática, porém, sugerem oito posições intermediárias com diferentes características que se aproximam gradativamente dos extremos, mas sempre misturando em porções diferentes características de ambas correntes.

Estratégias deliberadas ocorrem através de ações predeterminadas. Quando o estrategista pensa antes de agir, ele está planejando a estratégia a ser deliberada. Planejar mostra a intenção da corporação, contém os objetivos da estratégia e descreve como a organização deve agir para atingir o sucesso. Organizações que planejam têm as vantagens de direção, comprometimento, coordenação, otimização e programação.

Diversos autores se dedicaram a observar organizações seguidoras de estratégias deliberadas que obtiveram sucesso (HIGLEY 2000; BOURLAKIS; BOURLAKIS, 2001), demonstrando a importância desse extremo do paradoxo.

\section{MUDANÇA ESTRATÉGICA}

Mudança estratégica pode ser vista como uma intervenção pelo estrategista por meio do uso de técnicas da ciência comportamental para se sobrepor à inércia organizacional (TICHY, 1983).

Mudança não é uma opção para as corporações, é uma necessidade. As organizações precisam se ajustar ao seu ambiente. Porter (1999, p. 14) afirma que as mudanças são necessárias, pois as empresas não suportam estar dois anos atrás de seus concorrentes. Elas podem reagir aos estímulos externos ou ser pró-ativas, moldando o ambiente da indústria.

As mudanças podem ser operacionais ou estratégicas. Mudanças operacionais dizem respeito à 
melhoria de performance e manutenção do sistema. Mudança estratégica lida com a criação de novas configurações entre as corporações e seus ambientes. Existem muitas razões para mudar, como, por exemplo, um movimento de diversificação, uma mudança tecnológica ou um novo projeto de produto.

A tensão existente na mudança estratégica é relativa às mudanças evolucionárias ou revolucionárias. Mudanças revolucionárias propõem que a organização rompa com o passado, pois uma ligação com esse leva a um estado de paralisia.

Para Marrick (1998, p. 98), a mudança revolucionária é a chave da liderança de mercado. Tushman e O'Reilly (1996, p. 28) sugerem que existe pelo menos um ponto na história de qualquer empresa que ela deve mudar revolucionariamente para evoluir rumo a um nível superior de desempenho. Caso perca esse momento, a organização começa a declinar.

Mudanças evolucionárias, por sua vez, pregam a melhoria através de pequenas mudanças. Elas ocorrem durante toda a história da empresa e são guiadas pelo aprendizado organizacional.

Brown e Eisenhardt (1997, p. 2) sugerem que a mudança evolucionária ou contínua representa um fator crítico de sucesso nas organizações. Complementam ainda afirmando que aparentemente essas mudanças contínuas são realizadas através da inovação de produtos ou mesmo pelas alterações contínuas neles.

O próximo tópico contextualiza a empresa investigada nesta pesquisa.

\section{CONTEXTUALIZAÇÃO DA EMPRESA}

A Companhia Energética do Estado de Pernambuco (Celpe) foi constituída como sociedade de economia mista em 1965, com a denominação de Companhia de Eletricidade de Pernambuco, a partir da fusão do Grupo Pernambuco Tramways com as funções desempenhadas pelo Departamento de Águas e Energia (DAE), ficando o controle acionário com o Governo do Estado. Em 1986 passou a ser denominada de Companhia Energética de Pernambuco.

Até a sua privatização, em fevereiro de 2000, a empresa era propriedade do Governo do Estado de Pernambuco, quando por meio do programa nacional de privatização passou para o controle da iniciativa privada.
No ano 2000, o consórcio das empresas ADL Energy S.A., Caixa de Previdência dos Funcionários do Banco do Brasil (Previ) e BB Banco de Investimento S.A (Banco do Brasil) arrematou em leilão de privatização o controle acionário da Celpe, composto por ações representativas de 79,62\% do capital total da empresa, pelo preço mínimo estabelecido de R \$1,8 bilhão. Ainda no exercício de 2000, esse consórcio adquiriu ações dos empregados da Celpe, que representavam $4,76 \%$ do capital total da empresa. Em dezembro de 2000, as empresas do consórcio controlador realizaram aumento de capital na Guaraniana, integralizando-o mediante a conferência à companhia de 84,38\% de ações da Celpe. No último trimestre de 2000, a Guaraniana realizou diversas aquisições de ações preferenciais da Celpe em bolsas de valores, representativas de $0,7 \%$ do capital total da empresa, detendo no fim do exercício 85,08\% do capital total da Celpe. Esse consórcio já era dono das companhias energéticas da Bahia (Coelba) e do Rio Grande do Norte (Cosern).

Antes da privatização, a empresa chegou a contar com quase 5 mil empregados diretos; porém, hoje conta com cerca de 1.731 funcionários, resultado dos processos de transformações pelos quais passou desde a sua privatização.

Enquanto esteve subordinado ao Governo do Estado, o processo decisório da empresa era local, gozando de plena autonomia administrativa. Porém, as estratégias e planejamentos eram voltados para o atendimento de objetivos políticos, como geração de caixa para cobertura das despesas do Estado e meio para acomodação das forças políticas locais.

Ao ser privatizada, a empresa passou a atuar sobre um novo contexto operacional, integrando um grupo cujo capital era em sua maioria nacional, mas com um arranjo legal que garantia o controle a um grupo internacional, mais especificamente o Grupo Iberdrola, uma multinacional espanhola do setor elétrico.

Nesse período, o controle da gestão local se dava sob a perspectiva financeira. A holding não exercia papel executivo, e embora indicasse os principais postos de controle da empresa, essa ainda gozava de relativa autonomia.

Nos anos de 2001 e 2002, o setor elétrico passou por uma série de alterações, em parte devido ao racionamento e à crise cambial, quando muitas empresas haviam se endividado em moeda 
estrangeira, sem qualquer proteção financeira. A Celpe, contudo, nesse período foi afetada apenas pela queda de receita, e o Consórcio Guaraniana enfrentou prejuízos expressivos, o que limitou os investimentos na Celpe.

A partir desses acontecimentos iniciaramse algumas tensões entre os acionistas, quando os majoritários Previ e Banco do Brasil passaram a reivindicar maior participação no controle das empresas. Em 2003 foi celebrado um novo acordo de acionistas, no qual dessa vez a proporcionalidade do capital passaria a definir o controle da gestão. Decorrente desses processos de reestruturação do grupo, em 2004 o Consórcio Guaraniana passou a ser denominado de Grupo Neoenergia.

As transformações não se restringiram ao nome da holding; essa agora passava a exercer papel executivo. As diretorias das empresas foram extintas, passando a ser denominadas de Superintendências, e cada uma estaria subordinada diretamente a um diretor da holding, que, legalmente, ocuparia as posições de diretor, com a mesma denominação nas empresas controladas. Assim, o diretor de Planejamento e Controle da Neoenergia, seria também o diretor de Planejamento e Controle de todas as empresas. Os superintendentes de Planejamento e Controle das empresas seriam os responsáveis locais, estando subordinados ao presidente local e ao seu diretor respectivo na bolding.

A estratégia de integração no contexto corporativo passou a enfatizar uma maior sinergia, em detrimento da responsividade local, através de uma maior integração, visando à alavancagem de recursos, integração das atividades e alinhamento de posições entre as empresas do Grupo. Nessa nova estrutura matricial, o controle corporativo passou a ser através do estilo de controle de planejamento, em que o controle se dá através da supervisão direta, e não apenas pelo monitoramento dos objetivos financeiros e estratégicos, como ocorria na fase em que o controle se baseava nos estilos de controle financeiro e de estratégia, na fase em que a Iberdrola era o responsável pela operação do negócio (DE WIT; MEYER, 2004, p. 300).

Após a estruturação da holding, a empresa passou por uma estruturação interna com drástica redução dos postos executivos, que foram reduzidos quase à metade. Embora não tenha havido a diminuição de níveis hierárquicos, a empresa conta com apenas cinco níveis.
O contexto de operação da empresa é o de um setor concentrado, atuando como monopólio regulado pela Agência Nacional de Energia Elétrica. Seu mercado se divide em dois segmentos: o de alta e o de baixa tensão. No de baixa tensão, os consumidores são considerados "cativos", pois só podem comprar energia da distribuidora. Porém no ambiente dos clientes de alta tensão, esses podem escolher o fornecedor de energia, que pode ser fornecida por qualquer empresa do País, sendo através de acordos de cogeração de energia ou por meio de aquisição em leilão, uma vez que a rede de transmissão e distribuição de energia do País está interligada.

A empresa possui 1.731 empregados, atende 2.605.286 consumidores distribuídos em 186 municípios de Pernambuco, e um município na Paraíba. $\mathrm{O}$ patrimônio da empresa corresponde a $\mathrm{R} \$ 1,1$ milhão e apresentou receitas operacionais de cerca de $\mathrm{R} \$$ 2,5 milhões em 2005.

\section{CONSTRUÇÃO DO INSTRUMENTO DE MENSƯRAÇÃO DO PROCESSO DE FORMULAÇÃO ESTRATÉGICA}

A partir do conhecimento obtido na fase exploratória do estudo, foram identificadas três dimensões principais que formam a base do processo de formulação estratégica. Cada dimensão é mensurada por meio de uma escala composta de dez itens.

O trabalho de De Wit e Meyer (2004) sobre o processo, conteúdo e contexto estratégico foi utilizado como referência para o desenvolvimento dos itens, pois os autores apresentaram um amplo referencial teórico e enfatizaram a existência dos paradoxos no processo de formulação estratégica.

Cada escala é formada por dez itens. Estes itens foram extraídos da literatura e fazem referência a características encontradas nos estrategistas. Buscaram-se características fáceis de serinterpretadas pelos respondentes e relevantes para a mensuração do processo de formulação estratégica.

É ainda possível identificar que cada escala aborda os dois extremos dos paradoxos observados por De Wit e Meyer (2004, p. 13). Como forma de operacionalizar a pesquisa, foram desenvolvidos cinco itens compostos de características de um lado da tensão existente e os demais cinco itens abordando a outra corrente do paradoxo. 
A escala utilizada é tipo Likert e varia entre 1 e 5 pontos. O grau de concordância cresce conforme maior for o número de pontos assinalados. O ponto 3 foi utilizado como neutro. As escalas utilizadas são de natureza ordinal. Esse tipo de escala permite aferir se determinado objeto tem mais ou menos de uma característica que outro objeto, porém não permite quantificar essa diferença. Para escalas ordinais é aconselhado o uso de técnicas de análise não paramétrica (MALHOTRA, 2006, p. 418).
É importante ressaltar que o objeto deste estudo é o indivíduo, portanto, as escalas foram preparadas em primeira pessoa com intuito de facilitar a interpretação dos itens pelos respondentes.

$\mathrm{Na}$ formulação dos questionários as escalas compuseram um bloco único de perguntas com seus itens distribuídos aleatoriamente para induzir o respondente a ler todos os itens antes de responder.

Os itens das escalas podem ser observados nas Tabelas 1, 2 e 3.

TABELA 1 - Escala de mensuração do pensamento estratégico

\begin{tabular}{|c|c|c|}
\hline Dimensão & $\begin{array}{l}\text { Posicionamento } \\
\text { Paradoxo }\end{array}$ & Item \\
\hline \multirow[t]{10}{*}{ Pensamento } & Lógico & $\begin{array}{l}\text { Costumo realizar uma reflexão crítica sobre minhas crenças e forma de } \\
\text { pensamento. }\end{array}$ \\
\hline & Lógico & $\begin{array}{l}\text { Realizo análise do ambiente interno da empresa e do setor em que ela atua } \\
\text { antes de formular estratégias. }\end{array}$ \\
\hline & Lógico & $\begin{array}{l}\text { Testo minhas crenças organizacionais com o objetivo de melhorá-las e poder } \\
\text { aplicá-las. }\end{array}$ \\
\hline & Lógico & Testo minhas suposições para evitar basear as estratégias apenas na intuição. \\
\hline & Lógico & Desenvolvo estratégias de maneira formal, seguindo uma lógica clara. \\
\hline & Criativo & Utilizo a imaginação como fonte de criação estratégica. \\
\hline & Criativo & $\begin{array}{l}\text { Sou intuitivo na formulação de estratégias e me baseio no meu entendimento } \\
\text { sobre as coisas. }\end{array}$ \\
\hline & Criativo & Formulo estratégias com base na minha forma de pensar e ver as coisas. \\
\hline & Criativo & $\begin{array}{l}\text { Acredito que estratégias surgem de boas ideias e não de boas observações } \\
\text { sobre os fatos. }\end{array}$ \\
\hline & Criativo & Formulo estratégias com base na criatividade. \\
\hline
\end{tabular}

TABELA 2 - Escala de mensuração da formação estratégica

\begin{tabular}{lll}
\hline Dimensão & $\begin{array}{l}\text { Posicionamento } \\
\text { Paradoxo }\end{array}$ & Item \\
\hline Formação & Deliberada & $\begin{array}{l}\text { Acredito que um plano estratégico deva ser completamente finalizado antes de } \\
\text { ser iniciada sua execução. }\end{array}$ \\
& Deliberada & Crio estratégias com orientação de longo prazo. \\
\hline
\end{tabular}


TABELA 2 - Escala de mensuração da formação estratégica

\begin{tabular}{lll}
\hline Dimensão & $\begin{array}{l}\text { Posicionamento } \\
\text { Paradoxo }\end{array}$ & Item \\
\hline Formação & Deliberada & $\begin{array}{l}\text { Documento e torno explícito os planos estratégicos definidos para o negócio } \\
\text { ou atividade. }\end{array}$ \\
& Deliberada & $\begin{array}{l}\text { Traço metas e/ou objetivos bem definidos para guiar as estratégias. } \\
\text { Acredito que uma boa estratégia deve ser capaz de descrever as ações das pessoas, } \\
\text { evitando improvisos. }\end{array}$ \\
& $\begin{array}{l}\text { Creio que uma estratégia também pode ser construída ou modificada na medida } \\
\text { em que as ações vão sendo realizadas. }\end{array}$ \\
& $\begin{array}{l}\text { Acredito que as estratégias surgem no dia a dia, à medida que as coisas vão } \\
\text { sendo realizadas. }\end{array}$ \\
& $\begin{array}{l}\text { Acredito que planos estratégicos podem surgir à medida que se identificam novas } \\
\text { oportunidades de ação. }\end{array}$ \\
& $\begin{array}{l}\text { Estou certo que novas estratégias podem surgir de experiências ou iniciativas } \\
\text { das pessoas. }\end{array}$ \\
Emergente & Crio estratégias que são na essência flexíveis. \\
\hline
\end{tabular}

TABELA 3 - Escala de mensuração da mudança estratégica

\begin{tabular}{lll}
\hline Dimensão & $\begin{array}{l}\text { Posicionamento } \\
\text { Paradoxo }\end{array}$ & Item \\
\hline Mudança & Revolucionária & $\begin{array}{l}\text { Percebo que as mudanças com melhores resultados são aquelas que reinventam o } \\
\text { modo de funcionar do negócio ou da atividade. }\end{array}$ \\
Revolucionária & $\begin{array}{l}\text { Implemento mudanças de grande impacto e com velocidade para minimizar a } \\
\text { resistência das pessoas. }\end{array}$ \\
Revolucionária & $\begin{array}{l}\text { Acredito que para mudar é preciso ter coragem para romper com a situação } \\
\text { existente indesejável. }\end{array}$ \\
Revolucionária & $\begin{array}{l}\text { Desenvolvo habilidades para realizar grandes mudanças na estratégia } \\
\text { considerando a pressão dos concorrentes ou novas exigências do governo. }\end{array}$ \\
& $\begin{array}{l}\text { Estou certo que para ocorrer uma mudança estratégica é necessário ocorrer uma } \\
\text { grande mudança organizacional. }\end{array}$ \\
Evolucionária & $\begin{array}{l}\text { Acredito na capacidade de aprendizado da empresa e que as mudanças devem } \\
\text { acompanhar o ritmo deste aprendizado. }\end{array}$ \\
Evolucionária & Creio que a mudança é algo naturalmente presente no dia a dia de uma empresa. \\
Evolucionária & $\begin{array}{l}\text { Percebo que alterações em rotinas e processos são coisas que precisam de certo } \\
\text { tempo para se entender, testar e aplicar. }\end{array}$
\end{tabular}


TABELA 3 - Escala de mensuração da mudança estratégica

\begin{tabular}{lll}
\hline Dimensão & $\begin{array}{l}\text { Posicionamento } \\
\text { Paradoxo }\end{array}$ & Item \\
\hline Mudança & Evolucionária & $\begin{array}{l}\text { Entendo que em minha empresa não há uma única pessoa com força } \\
\text { suficiente para realizar uma grande mudança que altere a estratégia. }\end{array}$ \\
& Evolucionária & $\begin{array}{l}\text { Implemento várias pequenas mudanças organizacionais que cumulativamente } \\
\text { se tornarão uma grande mudança na estratégia da empresa. }\end{array}$ \\
\hline
\end{tabular}

Com o objetivo de conhecer melhor a amostra e aprofundar as análises foram incluídas três questões nominais (gênero, cargo e área de graduação) e quatro questões ordinais (grau de formação acadêmica, nível hierárquico ocupado na empresa, tempo de atuação profissional e tempo no cargo).

\section{MÉTODO}

A metodologia adotada possui um caráter exploratório-descritivo. O estudo exploratório serve de base para a formulação das hipóteses, isolando variáveis e relações-chave para análises descritivas (MARCONI; LAKATOS, 2002, p. 20). Essa fase do estudo se caracterizou pela revisão da literatura existente e culminou com a construção do instrumento de mensuração do processo de formulação estratégica em âmbito individual.

A pesquisa descritiva tem como principal objetivo a descrição de algo (MALHOTRA, 2006). $\mathrm{Na}$ presente pesquisa o fenômeno observado é o processo individual de formulação estratégica.

As informações sobre a empresa estudada foram obtidas através da análise de dados secundários e foram reforçadas pelos achados das análises descritivas.

Neste estudo foram utilizadas, além de estatísticas descritivas, as técnicas de análise multivariadas e a correlação não paramétrica de Spearman. A Figura 3 traz o desenho metodológico.

\section{ANÁLISE DE DADOS}

Para realização do estudo foram obtidos 55 questionários através de um survey on-line. Os respondentes são em sua totalidade executivos de uma grande empresa do setor energético brasileiro. Todos os níveis hierárquicos executivos da organização tiveram representação na amostra, sendo presidente o nível mais elevado e gestor, o menos elevado. A amostra mínima para realização do estudo, segundo Hair et al. (2006, p. 112), é de cinco respondentes para cada variável da escala. Neste estudo foram utilizadas escalas de dez itens, totalizando, então, um número mínimo exigido de 50 questionários respondidos para que as análises multivariadas pudessem ser executadas.

As análises descritivas foram utilizadas como base para a contextualização da empresa, juntamente com os dados obtidos através da desk research, e serviram de base para que os pesquisadores se certificassem da qualidade dos dados. As observações de dispersão realizadas estão dentro do que se é esperado de uma pesquisa no campo das ciências sociais.

Como base para as análises multivariadas foi elaborada uma hipótese nula para este estudo.

H0 - Não há correlação entre as dimensões da formulação estratégica (pensamento, formação e mudança) e a "formação acadêmica", o "nível hierárquico", o "tempo de atuação profissional" e o "tempo no cargo" dos indivíduos estudados.

\section{ANÁLISE DE CONFIABILIDADE E DE FATOR}

As três escalas utilizadas foram submetidas à técnica de análise fatorial, que possui o objetivo de analisar as relações internas entre um dado número de varáveis e explorar os fatores latentes comuns a esses itens. O objetivo é encontrar um meio de condensar a informação em um número menor de variáveis (fatores), com o mínimo de perda aceitável (HAIR et al., 2006, p. 17). Para testar a confiabilidade das 


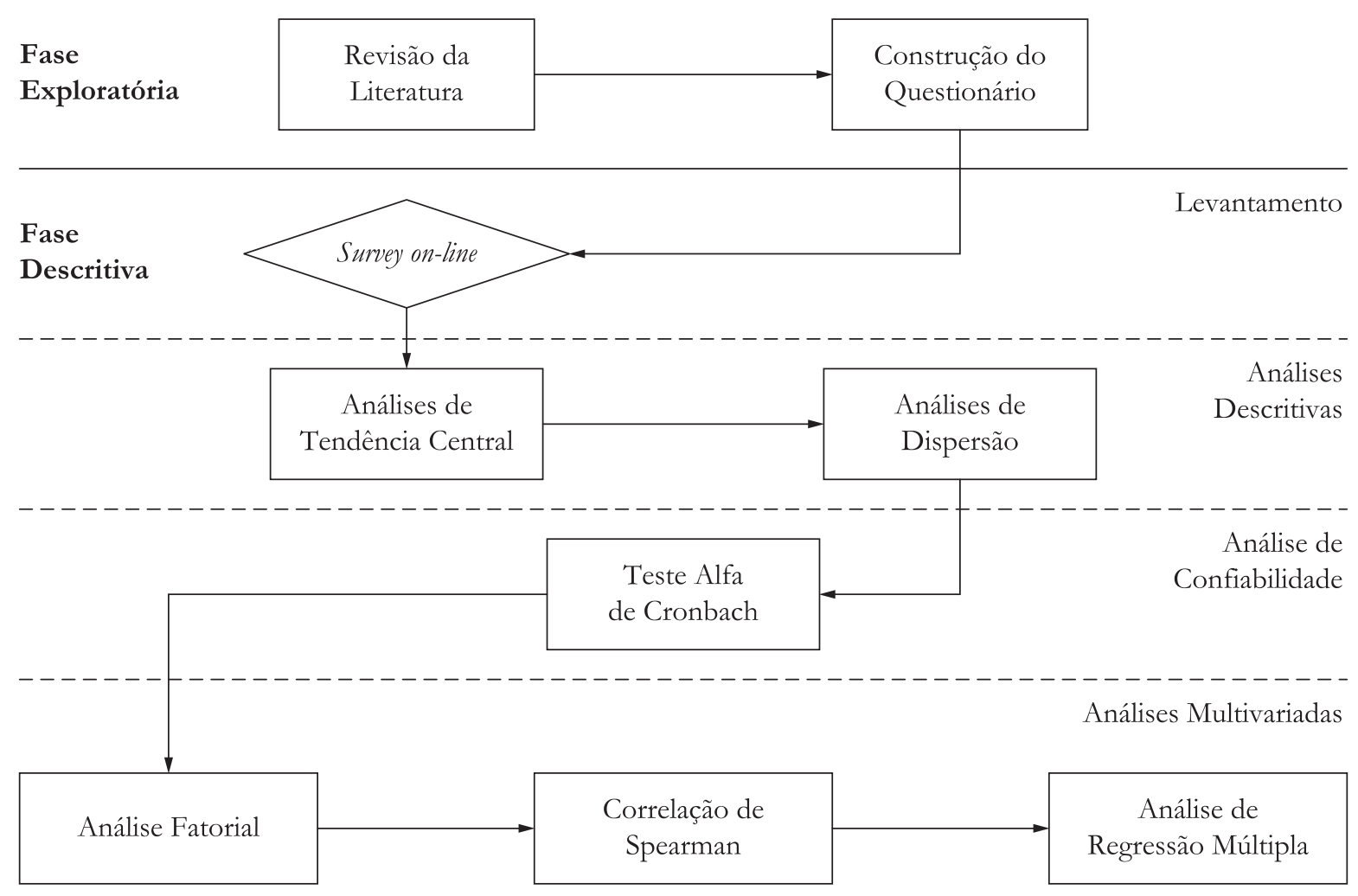

FIGURA 3 - Desenho metodológico

escalas foi feito o uso da técnica Alfa de Cronbach. Essa medida consiste em calcular a média de todos os coeficientes de tendência central que podem dividir a escala. Esse coeficiente varia de 0 a 1.

Os valores esperados de confiabilidade para o Alfa de Cronbach, segundo Malhotra (2006,p. 277), são de no mínimo 0,6. Índices iguais ou inferiores a esse não possuem consistência interna suficiente.

Segundo Hair et al. (2006, p. 128), a carga fatorial para uma amostra de 50 questionários é de no mínimo 0,75 , e para 60 questionários o indicado é 0,70 . Neste estudo, com amostra de 55 respondentes, as cargas acima de 0,725 foram assumidas como satisfatórias. Variáveis com cargas inferiores a essas foram excluídas para não comprometerem as análises. Para sua consistência interna, a análise fatorial deve possuir significância igual ou menor a 0,005. A medida de adequação da amostra de Kaiser-Meyer-Olkin é um índice utilizado para avaliar a adequação da análise fatorial, que varia de 0 a 1 .
Índices acima de 0,5 são considerados altos, ou seja, a análise fatorial é adequada (MALHOTRA, 2006, p. 549). Outros índices de adequação da matriz de correlação fatorial existente é o teste de esfericidade de Bartlett, em que é calculado o qui-quadrado e o grau de liberdade. Para o qui-quadrado, quanto maior o seu valor absoluto apresentado, mais adequada é a matriz (MALHOTRA, 2006, p. 550). O grau de liberdade indica a partir de quantos valores conhecidos os demais não estão livres para variar (LEVINE; BERENSON; STEPHAN, 2000, p. 291), e nesse caso espera-se os maiores valores possíveis.

A escala sobre pensamento estratégico obteve o índice alfa de confiabilidade de 0,703 após a exclusão de uma variável. A matriz resultante da análise de fatores rotacionada pelo método varimax em três interações pode ser observada na Tabela 4. O KMO observado foi de 0,727 , com 36 graus de liberdade e qui-quadrado de 100,744 com significância de 0,000 . 
TABELA 4 - Análise de fatores da escala de pensamento estratégico

\begin{tabular}{lcc}
\hline \multicolumn{1}{c}{ Itens } & 1 & 2 \\
\hline Testo minhas suposições para evitar basear as estratégias apenas na intuição. &, 755 \\
Desenvolvo estratégias de maneira formal, seguindo uma lógica clara. &, 786 &, 743 \\
Sou intuitivo na formulação de estratégias e me baseio no meu entendimento sobre as coisas. &, 747 \\
Formulo estratégias com base na minha forma de pensar e ver as coisas. &, 741 \\
Formulo estratégia com base na criatividade. & \\
\hline
\end{tabular}

As variáveis encontradas receberam os títulos de "pensamento lógico", para o primeiro fator, e "pensamento criativo", para o segundo fator.

A escala sobre formação estratégica obteve o índice alfa de confiabilidade de 0,779 . A matriz resultante da análise de fatores rotacionada pelo método quartimax em seis interações pode ser observada na Tabela 5. O KMO observado foi de 0,759 , com 45 graus de liberdade e qui-quadrado de 168,902 com significância de 0,000.

TABELA 5 - Análise de fatores da escala de formação estratégica

\begin{tabular}{lcc}
\hline \multicolumn{1}{c}{ Itens } & 1 & 2 \\
\hline $\begin{array}{l}\text { Creio que uma estratégia também pode ser construída ou modificada na medida em que } \\
\text { as ações vão sendo realizadas. }\end{array}$ &, 743 & 3 \\
$\begin{array}{l}\text { Acredito que as estratégias surgem no dia a dia, à medida que as coisas vão sendo } \\
\text { realizadas. }\end{array}$ &, 776 \\
$\begin{array}{l}\text { Acredito que um plano estratégico deve ser completamente finalizado antes de se iniciar } \\
\text { sua execução. }\end{array}$ &, 849 \\
Crio estratégias com orientação de longo prazo. &, 832 \\
Traço metas e/ou objetivos bem definidos para guiar as estratégias. &, 761 \\
\hline
\end{tabular}

As variáveis encontradas receberam os títulos de "formação emergente", para o primeiro fator, "formação deliberada", para o segundo fator, e "planejamento", para o terceiro fator.

A escala sobre pensamento estratégico obteve o índice alfa de confiabilidade de 0,738 após a exclusão de quatro itens. A matriz resultante da análise de fatores rotacionada pelo método varimax em três interações pode ser observada na Tabela 6 . O KMO observado foi de 0,648, com 15 graus de liberdade e qui-quadrado de 69,169 com significância de 0,000 .

As variáveis encontradas receberam os títulos de "mudanças revolucionárias", para o primeiro fator, e "mudanças evolucionárias", para o segundo fator. Os fatores encontrados serviram como insumo para o teste de hipótese nula. A correlação não paramétrica de Spearman é o tema central do próximo item. 
TABELA 6 - Análise de fatores da escala de pensamento estratégico

Itens

Percebo que as mudanças com melhores resultados são aquelas que reinventam o modo de

funcionar do negócio ou da atividade.

Acredito que para mudar é preciso ter coragem para romper com a situação existente indesejável.

Creio que a mudança é algo naturalmente presente no dia a dia de uma empresa.
1

,918

\section{CORRELAÇÃO DE SPEARMAN}

A partir dos fatores latentes identificados, uma matriz de correlação paramétrica de Spearman foi construída. A correlação de Spearman constitui um fundamento conceitual para a análise de regressão múltipla (MALHOTRA, 2006, p. 497). Pode-se observar na Tabela 7 o resumo das correlações.

TABELA 7 - Resumo das Correlações de Spearman

\begin{tabular}{lccc}
\hline & Formação acadêmica & Nível hierárquico & Tempo de atuação profissional \\
\hline Formação deliberada &, $369^{* *}$ &,$- 535^{* *}$ &, $352^{* *}$ \\
\hline
\end{tabular}

Nota: **Sig. 0,001 .

\section{ANÁLISE DE REGRESSÕES MÚLTIPLAS}

Após a identificação dos fatores, esses foram submetidos à análise de correlação de Spearman, que identificou três correlações com significância inferior a 0,001. Essas correlações foram mais bem analisadas por meio do método de regressão múltipla linear, que envolve uma única variável dependente e duas ou mais variáveis independentes. O objetivo da análise de regressão múltipla é prever as alterações na variável dependente em resposta às variações nas variáveis independentes (HAIR et al., 2006, p. 18).

Nas análises de regressão é importante observar o coeficiente de determinação $\mathrm{R}^{2}$, que mede a proporção da variação, explicada pela variável independente no modelo de regressão. $\mathrm{O}$ coeficiente de determinação é calculado pela soma dos quadrados, devido à regressão, e dividida pela soma total dos quadrados (LEVINE et al., 2000, p. 529). A variação do $R^{2}$ é entre 0 e 1 , e quanto mais próximo da unidade for, mais determinante são as variáveis independentes no comportamento da variável dependente.

A análise de regressões múltiplas considerou como variável dependente a "formação deliberada" e como variáveis independentes a "formação acadêmica", a "ordem do nível hierárquico" e o "tempo de atuação profissional".

O método de seleção de variáveis utilizado foi a estimação stepwise. Esse método de seleção consiste em selecionar as variáveis independentes mais significativas para o modelo. Elas são adicionadas conforme a significância de seus coeficientes de correlação parcial (HAIR et al., 2006, p. 175).

O modelo observado apresentou $\mathrm{R}^{2}$ ajustado de 0,315 , com desvio-padrão de 0,827 . Foram observados 54 graus de liberdade para o nível de significância de 0,000 . A variável independente "tempo de atuação profissional" foi excluída do modelo de acordo com o método stepwise adotado. A Figura 4 apresenta o modelo encontrado, relacionando o mapa mental com a tendência à formação deliberada, a formação acadêmica e a ordem do nível hierárquico do indivíduo. 


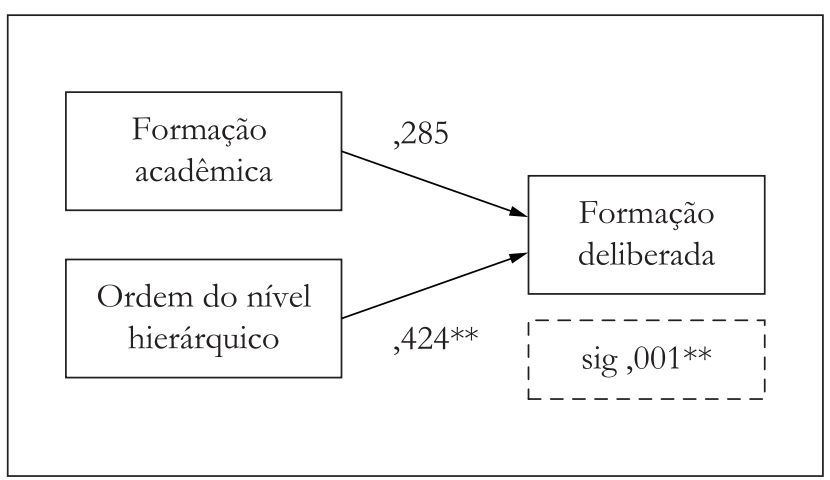

FIGURA 4 - Modelo proposto

A correlação encontrada entre a "ordem do nível hierárquico" e a "formação deliberada" está dentro dos limites de 0,4 e 0,6 e por isso pode ser considerada como moderada (BISQUERRA; SERRIERA; MARTÍNEZ, 2004, p. 147). É necessário frisar que pelo grande número de variáveis envolvidas nos processos estudados pelas ciências sociais aplicadas, os valores acima de 0,6 são dificilmente obtidos em ambientes não preparados.

Acredita-se que a negatividade do coeficiente observada está ligada à construção do questionário, que considera os maiores valores numéricos para os cargos mais baixos dentro da hierarquia da empresa.

Por meio dos resultados obtidos nas análises multivariadas, a hipótese nula foi negada. O tópico seguinte traz as conclusões que podem ser inferidas após as observações.

\section{CONCLUSÕES}

Por este estudo, pode-se identificar que o processo de formulação estratégico é formado por sete dimensões: "pensamento lógico"; "pensamento criativo"; "formação emergente"; "formação deliberada"; "planejamento"; "mudanças revolucionárias"; e "mudanças evolucionárias".

Essas mesmas dimensões foram propostas por De Wit e Meyer (2004). Na proposta dos autores, entretanto, a dimensão "formação deliberada" e "planejamento" aparecem unidas. A dimensão "planejamento" está ligada sobretudo aos itens relativos às estratégias de longo prazo e estabelecimento de metas, enquanto "formação deliberada" é formado pelos itens relativos à implementação das estratégias finalizadas.
Apesar de complementares, é possível que as estratégias deliberadas sejam direcionadas para o curto prazo ou possuam um pequeno número de metas, gerando assim uma diferença plausível entre "formulação deliberada" e "planejamento".

O principal achado da pesquisa é relativo à dimensão "formação deliberada". Foi observado que quanto mais elevado o nível hierárquico do indivíduo, maior é a relação com as estratégias deliberadas.

Observando que os indivíduos de maior nível hierárquico possuem afinidade com a formação estratégica deliberada e que esses mesmos executivos são responsáveis pela formulação da estratégia da empresa, conclui-se que a empresa do setor elétrico estudada tem forte tendência a implantar estratégias deliberadas.

Este estudo gera algumas implicações. Para a empresa estudada, é importante conhecer a forma de pensamento de seus executivos para observar o rumo que a empresa tende a tomar. Para a academia, foi formulado e testado um consistente instrumento de mensuração do processo de formulação estratégica no âmbito do indivíduo. Foram identificados os fatores da formulação estratégica, entre eles a dimensão "planejamento", que não aparecia isolada em estudos anteriores.

É necessário, entretanto, ressaltar as limitações deste estudo. Os resultados são apenas aplicados para a empresa estudada no tempo em questão, generalizações não são possíveis sem novos estudos. A falta de publicações sobre o processo de formulação estratégica em nível individual não permite estudos conclusivos, por isso novos estudos são necessários para que um melhor entendimento desse fenômeno seja construído.

Sugere-se que futuras pesquisas na área observem como o processo de formulação estratégica ocorre em outros setores. Acredita-se que por meio desses estudos seja possível identificar diferença nos mapas cognitivos entre estrategistas de diversos setores. O motivo dessas diferenças e a sua implicação para o sucesso organizacional é o desafio que fica para os estudiosos da estratégia.

\section{REFERÊNCIAS}

BERRIS, J. The ten faces of innovation: strategies for heightening creativity. 2nd ed. New York: E-learning Age, 2006. 
BISQUERRA, R.; SARRIERA, J. C.; MARTÍNEZ, F. Introdução à estatística: enfoque informático com o pacote estatístico SPSS. Porto Alegre: Artmed, 2004.

BONN, I. Developing strategic thinking as a core competency. Management Decision, v. 39, n. 1, p. 63-70, 2001.

BOSHYK, Y. Organizational learning worldwide: experience of leadership and organizational development. 2nd ed. New York: Palgrave Macmillan, 2002.

BOURLAKIS, M. A.; BOURLAKIS, C. A. Deliberate and emergent logistic strategies in food retailing: a case study of the greek multiple food retail sector. Supply Chain Management, v. 6, n. 1, p. 189, 2001.

BROWN, S. L.; EISENHARDT, K. M. The art of continuous change: linking complexity theory and time-paced evolution in relentlessly shifting organizations. Administrative Science Quarterly, v. 42, n. 4, p. 1-34, 1997.

CORTELLO, C. Fostering creativity. Industrial Engineer, v. 37, n. 10, p. 26, 2005.

DEWIT, B.; MEYER, R. Strategy: process, content, context. An international perspective. 2nd ed. Minneapolis/ St. Paul: West Publishing Company, 2004.

DILWORTH, R. L.; WILLIS, V. J. Organizational learning: images and pathways. 2nd ed. Florida: Krieger Publish, 2003.

EISENHARDT, K. M. Paradox, spirals, ambivalence: the new language of change and pluralism. Academy of Management Review, v. 85, n. 4, p. $708-705,2000$.

HAIR Jr., J. F. et al. Multivariate data analysis. 6th ed. New Jersey: Prentice Hall, 2006.

HIGLEY, J. Bass focuses on deliberate agenda. Hotel and Motel Management, v. 215, n. 19, p. 3, 2000.

JOHNSON-LAIRD, P. N. Mental models: towards a cognitive science of language, inference and consciousness. 2nd ed. Cambridge: Harvard University Press, 1983.

KAHNEMAN, D. Maps of bounded rationality: a perspective on intuitive judgment and choice. 2nd ed. Princeton: Prize Lecture, 2002.

LEVINE, D. M.; BERENSON, M. L.; STEPHAN, D. Estatística: teoria e aplicações. Rio de Janeiro: LTC, 2000.
MACHADO-DA-SILVA, C. L.; FONSECA, V. S. da; FERNANDES, B. H. R. Mudança e estratégia nas organizações: perspectivas cognitiva e institucional. Disponível em: $<$ http://members.lycos.co.uk/Dablium/ artigo18.htm>. Acesso em: 26 nov. 2006.

MALHOTRA, N. K. Pesquisa de marketing: uma orientação aplicada. 4. ed. São Paulo: Bookman, 2006.

MARCONI, M. A.; LAKATOS, E. M. Técnicas de pesquisa. 5. ed. São Paulo: Atlas, 2002.

MARRICK, C. Revolutionary change is key to market leadership. Credit Union Magazine, v. 64, n. 10, p. 45, 1998.

McGILL, I.; BROCKBANK, A. The organizational learning handbook: powerful techniques for education, professional development and training. 2nd ed. London: Routledge Falmer, 2004.

MINTZBERG, $H$. The fall and rise of strategic planning. Harvard Business Review, v. 72, n. 1, p. 107-114, 1994.

MINTZBERG,H.;LAMPEL, J. Reflecting on the strategy process. Sloan Management Review, v. 40, n. 3, 1999.

MINTZBERG,H.;AHLSTRAND, B.;LAMPEL,J. Safári de estratégia: um roteiro pela selva do planejamento estratégico. 2. ed. Porto Alegre: Bookman, 2000.

MINTZBERG, H.; WATERS, J. Of strategies deliberate and emergent. Strategic Management Journal, v. 6, n. 2, p. 257-272, 1985.

MOORE, M. The ten faces of innovation: IDEO's strategies for beating the devil's advocate. HR Human Resource Planning, v. 29, n. 3, p. 39, 2006.

MUSSELMAN, S. Linking culture, strategy builds business success. Hotel and Motel Management, v. 220, n. 8 , p. 14,2005 .

NUNES, M. F. Relações entre estratégias e estrutura organizacional: um estudo de caso na empresa de pesquisa, assistência técnica e extensão rural do estado de Mato Grosso do Sul. 2000. 226 f. Dissertação (Mestrado em Administração) - Universidade Federal do Rio Grande do Sul, Porto Alegre, 2000.

PORTER, M. Creatingadvantage. Executive Excellence, v. 16, n. 11 , p. $12,1999$.

RAIMOND, P. Two styles of foresight: are predicting the future or inventing it? Long Range Planning, v. 29 , n. 2, p. 208-214, 1996. 
REID, J. The emergent nature of strategy for hr professionals advice and insight from an expert. Canadian HR Reporter, v. 12, n. 10, p. 12, 1999.

REIN, R. 10 Ways to spark creativity at leadership retreats. Successful Meeting, v. 55, n. 11, p. 26, 2006.

STEINER, G. A.; KUNIN, H.; KUNIN, E. Formal strategic planning in the United States today. Long Range Planning, v. 16, n. 3, p. 12-17, 1983.

TICHY, N. Managing strategic change. 2nd ed. New York: John Wiley, 1983.

TUSHMAN, M. L.; O'REILLY III, C. A. Ambidextrous organizations: managing evolutionary and revolutionay change. California Management Review, v. 38, n. 4, p. 12, 1996.

WELCH, J. Pick great talent and develop them daily. Leadership Excellence, v. 22, n. 6, p. 12, 2005.

Recebido: 14/06/2009

Received: 06/14/2009

Aprovado: 10/08/2009

Approved: 08/10/2009 